\title{
ESTADOS DISENTÉRICOS NA GRAVIDEZ E NO PUERPÉRIO
}

\author{
Aula pronunciada pelo Dr. Oscar Monteiro de \\ Barros no curso de especialisação Obstétrica, or- \\ ganisado pelo Prof. Raul Briquet, em Setembro \\ de 1941
}

\section{DR. OSCAR MONTEIRO DE BARROS}

Primeiro Assistente e Livre docente da Cadeira de Clínica de Moléstias Infectuosas e Tropicais da Faculdade de Medicina da Universidade de Sāo Paulo, chefe Prcf. Celestino Bourroul.

\section{Meus senhores,}

Foi com a máxima satisfação que aceitamos o honroso convite que nos fez o Prof. Briquet para que, durante este curso de especialisação obstétrica, vos disséssemos algo sobre os síndromos disentéricos na gravidez e no puerpério. Temos sobre o assunto prática já bem longa, mercê dos numerosos casos que temos tido ocasião de acompanhar na clínica particular e, muito especialmente, na Cadeira de Clinica Obstétrica da Faculdade de Medicina, a pedido do Prof. Briquet. Aproveitamos este ensejo para dizer da grande satisfação que temos tido ao prestar, nesse sentido, a nossa modesta colaboração à Cadeira de Obsterícia, pois temos verificado a dedicação e o interesse que o Prof. Briquet e seus dignos auxiliares prestam às pacientes internadas nas enfermarias daquele serviço. Com essa dedicação e esse interesse procura aquele punhado de competentes profissionais neutralisar, até um certo ponto, a deficiencia deploravel de recursos com que luta a Cadeira de Obstetricia, aquinhoada com orçamento quasi ridiculo e absolutamente insuficiente para promover assistencia às parturientes que buscam os recursos daquela instituição.

Podemos, inicialmente, afirmar que as manifestações disentéricas no curso da gravidez e do puerpério são muito frequentes e se revestem, não raramente, de excepcional gravidade. Essa é uma verdade que pode ser atestada por todos aqueles que frequentam serviços de obstetrícia.

Quais são as razões dessa frequencia e dessa gravidade?

A nosso ver são várias e de vária natureza. Consideramos mais importantes as seguintes: 
a) causas anatômicas $\left\{\begin{array}{l}\text { compressão e deslocamento } \\ \text { compressão e irritação de nervos } \\ \text { estase venosa } \\ \text { hiperemia ativa }\end{array}\right.$

b) causas mecânicas ou traumáticas $\left\{\begin{array}{l}\text { contração do útero durante o parto } \\ \text { passagem do feto pelo canal do parto }\end{array}\right.$

c) causas biológicas $\left\{\begin{array}{l}\text { coproestase, modificações vasculares e secretórias, cpn- } \\ \text { dicionando: } \\ \text { virulencia dos germes da flora normal } \\ \text { reativação da virulencia de germes patogênicos } \\ \text { implantação e multiplicação de novos germes patogênicos }\end{array}\right.$

d) causas gerais $\left\{\begin{array}{l}\text { aquilia ou hipoquilia } \\ \text { avitaminoses } \\ \text { sublimentação } \\ \text { anemia } \\ \text { verminoses }\end{array}\right.$

Estudemos mais particularmente cada uma destas causas.

a) anatômicas: a compressão e deslocamento do retosigma pelo tumor uterino; a estase venosa daí decorrente, que se traduz. pelas crises hemorroidárias tão frequentes na fase final da gravidez; a irritação dos filetes nervosos e conseqüentes fenômenos vasculares e secretórios, ao lado da hiperemia ativa que acompanha a fase final da gestação e o trabalho de parto constituem, somados, causas adjuvantes importantes de aparecimento ou agravamento de sindromos disentéricos durante a fase final da gestação ou durante o puerpério.

b) causas mecânicas ou traumáticas: a movimentação e a contração do útero dur nte o trabalho de parto e a passagem do feto através o canal do parto traumatisam as paredes do reto, do sigmoide e de outros segmentos intestinais e assim se formam lesões em que facilmente se implantam os germes patogênicos ou se reativam processos inflamatórios ou ulcerosos, aparentemente curados.

c) causas biológicas: a coproestase, frequente nos últimos mêses de gravidez, as condições anatômicas, circulatórias, nervosas e secretórias que acabamos de examinar podem condicionar virulencia da flora normal do intestino, especialmente do colibacilo. Daí as colibacioses intestinais e urinarias, freqüentes na gravidez e no puerpério. Acresce que, pelas mesmas razões, os germes patogênicos, em estado de saprofitismo na luz do intestino grosso, quer em consequencia de estados disentéricos anteriores, quer sem antecedentes disentéricos, podem readquirir virulencia e desencadear estados disentéricos graves.

d) causas gerais: múltiplas são as causas de meṇor resistencia da gestante e da puérpera às infeções em geral e especialmente às de carater disentérico. Entre elas, por mais freqüentemente observadas, devemos lembrar os estados anêmicos, de subalimentação e de hipovitaminose. Outrossim, a hipoquilia e mesmo aquilia que acompanham certos estados anêmicos da gravidez acarretam anorexia e, con- 
sequente carencia alimentar. Destarte se forma círculo vicioso, de consequencias desastrosas para a gestante. Suprimida a ação bactericida do suco ácido do estômago, é facilitada a passagem de germes patogênicos ao intestino onde podem determinar aparecimento de sindromos disentéricos ou de intoxicação alimentar.

Sintomatologia: em suas linhas gerais, as manifestações disentéricas na gestação, não diferem das que se observam fóra dela: emissão dolorosa e freqüente de dejeções com catarro, sangue ou pus, acompanhadas ou não de febre e tenesmo. Nas disenterias gravídicas, porem, são mais acentuadas a adinamia, a anemia, o mau estar geral, a tendência ao colapso da circulação periférica e a rebeldia ao tratamento.

Diagnóstico: ante um caso de disenteria, mister se faz que, rapidamente, se realise o diagnóstico etilológico e se estudem as condições gerais da paciente para que a mais eficiente terapêtica, causal e geral, seja sem demora instituida. P'elas razões já expostas, ainda mais urgentemente' deve ser iniciada essa completa terapêutica quando se trate de gestante ou puérpera. Com que meios contamos para chegar a esse diagnóstico etiológico e para bem avaliar as condições gerais da paciente?

São eles os seguintes: I) anamnese, II) observação clínica, III) exame das fezes (a) direto, b) cultura, IV) retrosigmoidoscopia, $V^{T}$ ) hemograma, VI) prova de Katsh.

Passemos rapidamente em revista cada um desses meios.

I) a anamnese, dará a conhecer a existência de surtos disentéricos anteriores e o resultado das pesquisas então praticadas, o modo de aparecimento do surto atual ( si acompanhado ou não de fenômenos gerais de intoxicação, si surgido de forma muito aguda, febril ou de forma crônica $a b$-initio), e será assim de grande utilidade à elucidação do diagnóstico.

II) a observação clínica permite verificar a existência ou não de febre, o grau de intoxicação, a pressão arterial, o número de dejeções, o estado de desidratação, a intensidade das cólicas e do tenesmo. $O$ conjunto desses dados é de excepcional importância para instituição da adequada terapêutica.

III) o exame das fezes trará, na maior parte dos casos, o diagnóstico etiológico. Será: a) direto ou b) cultural.
a) exame direto
1) Ameba disentérica
2) Flagelados $\left\{\begin{array}{l}\text { Chilomastix } \\ \text { Tricomonas } \\ \text { Giardia }\end{array}\right.$
3) Infusórios - Balantidium coli
4) Larvas de Strongiloides estercoralis

1) E' preciso que o analista seja prático e saiba bem distinguir a. Entameba disenterie, hematófaga, patogênica, das demais amebas, não patogênicas, muito mais frequentes. A presença da ameba pato- 
gênica é um dado da maior importancia e mostrará desde logo a causa do sindromo observado.

2) Quanto aos flagelados, devem ser levadas em linha de conta as Giardias, especialmente si muito numerosas e sob a forma vegetativa. Em relação à Trichomonas e Chilomastix, diremos que sua presença não deve desde logo satisfazer o clínico, pois freqüentemente a presença desses protozoários apenas testemunha a irritação intestinal, cuja verdadeira causa reside na Entameba histolítica ou nos Bacilos disentericos. Todavia, si pesquizas repetidas só revelam, constantemente, sua presença, mister se faz que a terapêutica vise essa possivel etiologia.

3) O Balandium coli é raro entre nós. Mas seu encontro deve necessariamente ser levado em linha de conta.

4) As larvas de Strongiloides estercoralis, são frequentemente, no nosso meio, causas de sindromos disentéricos e de diarréias crônicas rebeldes e graves. Deve, pois, sua presença merecer a atenção do clínico.

b) Si o exame direto não foi concludente, será feita a cultura do material, que poderá revelar:

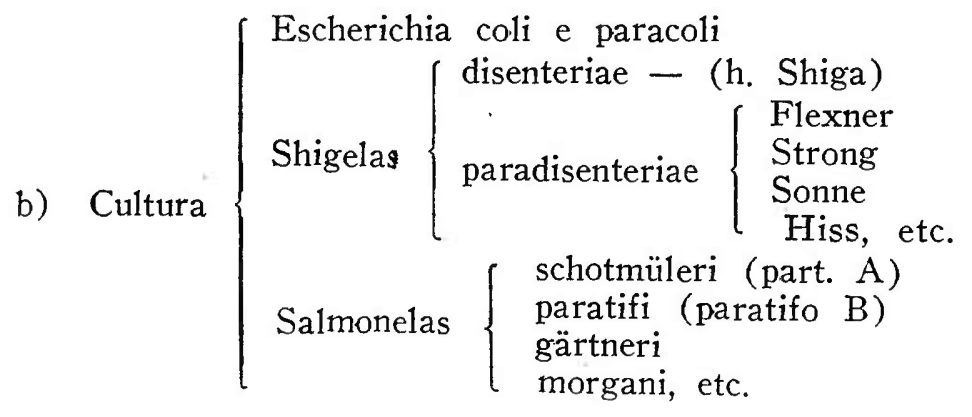

O encontro de qualquer destas bactérias se reveste de importância e freqüentemente trará a solução do problema etiológico. A questão do coli e do parocoli é muito discutida, mas geralmente é admitido pelos autores que esses germes, nas condições apresentadas pelas gestantes e pelas puerperas, já anteriormente por nós estudadas, podem se tornar patogênicos, determinando destarte sindromos disentéricos importantes. O testemunho do aumento de virulências desse grupo está na sua passagem ao aparelho urinário, de que resultam as pielites tão frequentes na gravidez, e na sua propagação ao intestino delgado e ao aparelho excretor da bile. Assim, nos casos de síndromos disentéricos em grávidas e puérperas, si pesquisas reiteradas e cuidadosas só sevelam o coli, ele deve ser responsabilisado. Quanto às Shigelas, seu encontro trará geralmente a certesa da etologia. As Salmonelas têm papel discutivel na gênese de sindromos disentericos crônicos, mas sua presença, quando sejam o único germe patogênico, merecerá atenção.

IV) a retosigmoidoscopia deve ser praticada em todos os casos de disenteria crônica e mesmo subaguda, maximé durante a gestação 
e puerpério. Ele permite freqüentemente um diagnóstico seguro, seja pelo aspeto das lesões, seja pelo exame do material colhido diretamente. Ainda quando a retosigmoidospia não possa concorrer para elucidação do diagnóstico ou quando este já tenha sido realizado por exames anteriores, ela fornecerá ao clínico informes importantissimos sobre a extensão e importancia das lesões e sobre a necessidade ou possivel eficiencia de tratamento local, que, amiúde, trará surpreendentes resultados.

V) $\mathrm{O}$ exame hematológico mostrará o grau de anemia e sua qualidade (si hiper ou hipocrômica); o estudo dos glóbulos brancos dirá sobre as condições de defesa da paciente e orientará o clínico a respeito de estados alérgicos ou supurativos. Desnecessário será encarecer o valor destes informes para orientação terapêutica.

VI) A prova de Katsch revelará as condições do quimismo gástrico e patenteará assim deficiencias dos fermentos digestivos ou de ácido clorídrico, cuja importancia nos estados disentéricos já foi focalisada anteriormente.

Só então, depois de cuidadosamente examinada sua paciente, ajudado de todos estes informes de laboratório, pode o clínico instituir terapêutica eficiente e de efeitos seguros nos graves e frequentes estados dișentéricos da gestação e do puerpério.

Terapêutica: deverá ser $a$ ) geral ou sintomática) e $b$ ) causal ou etiológica.

a) medicação geral

1) alimentação adequada

2) medic. ferruginosa, hepática e vitamínica

3) medic. da aquilia

4) hidratação

5) medic. vascular

6) medic. suprarenal

7) transfusões de sangue

8) medic. antiespasmódica e sedativa

1) A alimentação deve ser a um tempo substancial e de facil digestão. Os repastos devem ser de pequeno volume, amiudados e constituidos de liquidos, mingaus, sopas e puréias. O leite, de início, deve ser dado de mistura com parte igual de chá ou agua mineral. Salvo intolerancia pessoal, as coalhadas e os mingaus de farinhas finas, estão indicados. Os leites albuminosos e as farinhas albuminosas, quando bem tolerados, tem tambem indicação. Sopas grossas, feitas com caldo de frango ou de carne (de arroz, massinha, farinhas), as puréias de batatas e de outros bolbos, bife-tea, geléias, ovos quentes ou escaldados, a maçã, os cozimentos de cereais, os doces em pasta (marmelada, goiabada) podem fazer parte do regime diário. A medida que a paciente melhore, vai-se impondo alimentação mais substancial e é grave erro mante-la então no regime de líquidos e mingaus, pois assim certamente se agravará o estado de anemia e de astenia em que ela se encontra. Logo será, pois, reforçada a alimentaçâo com carne, sob forma de bife de raspa, ou cozida, passada à máquina e com fígado mal cozido, sob forma de papa ou de almondega. 
2) Sempre que a anemia seja intensa, a ingestão de alimentos dificil, por anorexia ou vômitos, e o regime evidentemente deficiente em ferro è vitaminas, impõe-se a medicação ferruginosa (ferro reduzido, 1 a 2 grs., associado ao H.Cl., ou cloreto ferroso, 0,50 a $1 \mathrm{gr}$., ou citrato de ferro amoniacal, nas mesmas doses). Ao mesmo tempo, é da maxima conveniencia administrar doses generosas das vitaminas A, B e C, por via parenteral. A hepatoterapia, por meio de extratos totais ou, conforme o tipo de anemia, antianemicos, será evidentemente de grande vantagem.

3) Nos casos em que a prova de Katsch tenha revelado hipo ou aquilia, impõe-se, pelas razões já mencionadas, a medicação pelo H.Cl. (acido clorídrico oficinal, diluido ao terço $\mathrm{V}$ a X gotas, no meio das refeições, diuidas em agua), pela pepsina e pelos demais fermentos digestivos. Podem-se utilisar para esse fim os diferentes preparados existentes no mercado. A medicação cloridrica será tambem propinada em todos os casos em que se indica a terapêutica ferruginosa, conforme foi dito ha pouco.

4) Uma das tarefas mais importantes que compete ao clínico que tem a seu cargo o tratamento de um caso de disenteria, é a de compensar as grandes perdas aquosas, pela generosa administração de líquido pela boca e pelas vias subcutanea e venosa. Com esse fim, alem de permitir à doente ingestão de agua "per os" (o que nem sempre é possivel, na quantidade desejada) serão feitas injeções de soro glicosado isotonico e de soro fisiológico, subcutanea e venosamente, na dose de um a dois litros (segundo a intensidade das perdas). A via venosa é especialmente indicada e por ela se pode injetar facilmente, gota a gota, 1 a 2 litros nas 24 horas. Essa larga administração de líquidos evita as graves consequencias da desidratação e determina rápidas melhoras quanto ao estado de intoxicação do paciente.

5) A medicação vascular se impõe em todos os casos acompanhados de hipotensão arterial e de cianose. Será praticada, de maneira contínua, enquanto perdurarem os fenômenos vasculares. Serão injetadas, alternadamente: cardiazol, coramina, cardiazol-cfedrina, cafeina, veritol, canfora, etc.

6) As toxinas dos germes da disenteria, a cloropenia, a desidratação determinam insuficiencias das capsulas suprarenais, que será combatída com os extratos de "cortex, naturais ou obtidos por síntese, injetados em doses elevadas.

7) Uma das medicações com que mais se aproveitam as disentéricas é constituida pelas transfusões de sangue. Elas preenchem, de fato, várias indicações: são antianemicas, são antitóxicas e antiinfeciosas e são ainda medicação vascular, por aumentarem a massa circulante. Com seu uso, rapidamente se restauram as forças da paciente. Devem ser transfundidos 100 a $200 \mathrm{cc}$., a princípio diariamente por 3 a 4 dias e depois 2 a 3 vezes por semana até um total 
de um a dois litros, segundo as necessidades do caso. Nas pacientes em que não predomina anemia, mas sim os fenomenos vasculares e desidratação, tem indicação a plasmoterapia.

8) $\mathrm{O}$ tenesmo e as cólicas intestinais violentas, presentes em quasi todos os casos de disenteria grave, impedem o repouso e inflingem à doente disentérica sofrimento atroz, que exige tratamento sintomático, sedativo e calmante. Com esse fim serão utilisados a beladona e os preparados dela derivados, os barbitúricos e os opiáceos. Estes últimos, embora muito eficases têm o incoveniente de causar freqüentemente constipação. A aplicação de supositórios calmantes quando o reto não esteja demasiadamente intolerante, pode dar bons resultados. A medicação pelos sais de bismuto, pelos tánicos, que agem protegendo a mucosa e absorvendo toxinas, está tambem indicada. Os cisteres de colargal e de argirol $(0,20$ a $0,25 \mathrm{em}$ 200 de agua), aplicados com sonda retal longa, têm, por vezes, ação verdadeiramente calmante.

b) medicação casual ou etiológica: naturalmente ela dependerá do agente causal. Todavia, diremos que o tratamento de qualquer estado disentérico deverá se iniciar pela administração de sulfato de sódio (sulfato de sódio 30 grs., agua q. s. para 150 grs. Tome em tres porções iguais, de hora em hora). Essa medicação modifica consideravelmente o aspecto das dejeções, tem, geralmente, acentuada ação desintoxicante e prepara a mucosa para receber a ação do tratamento etiológico.

Consideraremos a seguir os estados disentéricos causados: 1) por protozoários, II) por vermes e III) por bacilos.

I) Protozoários: Amebas. Salvo condições gerais precarissimas, é de rigor a medicação emetínica. Si o estado da paciente for de molde a fazer temer a ação. tóxica dessa terapêutica, melhorar esse estado mediante tratamento geral intenso e iniciar a emetina o mais precocemente possivel, aliada aos demais medicamentos indicados nas amebiases (yatrem, enterovioformio, clisteres de yatrem ou de colargol e, mais tarde quando as condições da paciente o permitam, stovarsol, carbarson etc.). Flagelados. Verificada sua ação patogênica real, com as restrições expostas anteriormente, fazer, no caso da Giardia, tratamento pela atebrina e no dos demais flagelados, alem do tratamento sintomático pelas poções de bismuto e tanalbina, que nestes casos dão freqüentemente bom resultado, utilisar a terebintina, os preparados iodados (yatrem etc.) e os arsenicais (quando o estado geral o permita), especialmente stovarsol.

II) Vermes (anguilulas): Alem do tratamento sintomático, utilisar contra o Strogiloides estercoralis o processo advogado por Faust: violeta de genciana, em capsulas gelatinosas na dose de 0,06 , tres vezes ao dia por 12 a 20 dias, conforme a tolerancia. Tambem podem ser feitas instilações duodenais, por meio da sonda de Einhorn, de solução a $1 \%$, na dose de 25 cc., que, nos casos rebeldes, dá ótimos resultados. 
III) Bacilares. Nestes casos, dadas as condições geralmente precárias da paciente, têm especial importancia os tratamentos geral e sintomático, cujas bases já expuzemos. Alem disto, têm indicação as bucovacinas, os bacteriófagos, as autovacinas bucais e injetáveis. (estas especialmente indicadas nas formas crônicas), os clisteres medicamentosos. Sobre duas medicações, porem, desejamos insistir especialmente, pois, de tão eficases, podem se considerar quasi específicas: a) soroterapia e $b$ ) sulfamidoterapia.

a) Soroterapia. Nos casos muito agudos e profundamente tóxicos, em que não possa ser esperada a identificação do germe pelos processos bacteriológicos, sempre demorados, deve se lançar mão do soro polivalente, de boa procedencia, por via intramuscular, na dose de 50 a $100 \mathrm{cc}$. diariamente, repetindo as injeções, por dois a tres dias, conforme a evolução do caso. Sempre que possivel, usar de preferencia os soros específicos (anti-Shiga ou anti-Flexner). E' necessário assinalar, porem, que a soroterapia deve ser reservada aos casos sumamente graves e tóxicos.

b) Sulfamidoterapia. Desde que os preparados sulfamídicos entraram a ser utilisados na terapêutica humana, foi verificada sua eficácia nas disenterias bacilares. A literatura médica está cheia de trabalhos a esse respeito. De modo geral, pode se afirmar que todos os derivados do prontosil podem ser utilisados com vantagem, quer na clínica infantil, quer na dos adultos. Ultimamente, porem; tem sido observado que os preparados menos absorviveis, embora não determinem fortes concentrações sanguineas, agem, porisso mesmo, com mais intensidade no interior do intestino, razão pela qual vêm sendo preferidos. Estão nesse caso a sulguanidina e succinilsulfatiasol. As doses, conforme a gravidade dos casos, devem ser, para os adultos de $0,10,0,15$ ou 0,20 grs. por quilo de peso, nas 24 horas. Para as crianças, nos casos graves, 0,20 a 0,25 , nas primeiras 24 horas. Dividir a dose em porções iguais e administrá-las cada tres, quatro ou seis horas. Exemplo: uma gestante ou puérpera de 60 quilos, apresentando disenteria grave, tomaria $60 \times 0,20=12$ grs. nas 24 horas, que poderiam ser divididas em 8 doses de grama e meia, dadas cada tres horas, em 6 doses de 2 grs., dadas de quatro em quatro horas ou em 4 doses de 3 grs., dadas de 8 em 8 horas. E' necessário que, nas primeiras 24 horas a paciente seja despertada para absorver a medicação com regularidade, o que, aliás, é de rigor sempre que se institue sulfamidoterapia, sob qualquer indicação. Nossa experiencia com essa medicação é deveras favoravel, pois temos dela feito uso em numerosos casos, no que se refere ao primeiro preparado mencionado, alguns dos quais bem graves, sempre com resultados satisfatórios. As doses elevadas iniciais, devem ser mantidas por 24 ou 48 horas, mas, desde que se estabeleçam melhoras, devem ser diminuidas a 6 ou 4 grs., nas 24 horas. 